\title{
Comparative Evaluation of Antibacterial Efficacy of Giomers and Compomers against Streptococcus mutans and Lactobacillus acidophilus: An In Vitro Study
}

\author{
${ }^{1}$ Revathi M, ${ }^{2}$ Vijay Kumar CN, ${ }^{3}$ KS Suresh, ${ }^{4}$ Asima Banu, ${ }^{5}$ SK Shrinath, ${ }^{6}$ Sooraj J Satheebhai
}

\section{ABSTRACT}

Aim: An in vitro study to evaluate and compare the antibacterial efficacy of giomer and compomer against Streptococcus mutans (S. mutans) and Lactobacillus acidophilus (L. acidophilus).

Material and methods: Antibacterial activity of giomer (Beautifil flow plus, Shofu Inc., Kyoto, Japan) and compomer (Dyract XP, Dentsply, Germany) was assessed using the agar diffusion test, in triplicate. Test specimens for both the dental materials were prepared using a custom made teflon ring mold with a diameter of $6.5 \mathrm{~mm}$ and thickness of $2 \mathrm{~mm}$ and inserted into the punched wells $(6.5 \mathrm{~mm} \times 2 \mathrm{~mm})$ in the $\mathrm{BHI}$ agar, $0.2 \%$ chlorhexidine digluconate placed in other well acted as a control. The agar plates were incubated at $37^{\circ} \mathrm{C}$ for 24 hours, later size of the inhibition zones was measured (in $\mathrm{mm}$ ) by digital vernier caliper at three different points at 24 hours, 48 hours and 7 days interval. Results were tabulated and subjected to statistical analysis.

Results: Nearly $0.2 \%$ chlorhexidine, the control group showed an inhibition zone, whereas the restorative materials did not show the inhibition zone as well the antibacterial efficacy against $S$. mutans and $L$. acidophilus.

Conclusion: None of the hybrid esthetic restorative material tested in this study possesses antibacterial properties.

Keywords: Antibacterial, Caries resistance, Culture, Esthetic restorations.

How to cite this article: Revathi M, Kumar VCN. Suresh KS, Banu A, Shrinath SK, Satheebhai SJ. Comparative Evaluation of Antibacterial Efficacy of Giomers and Compomers against Streptococcus mutans and Lactobacillus acidophilus: An In Vitro Study. World J Dent 2018;9(6):505-512.

\footnotetext{
${ }^{1}$ Department of Pedodontics and Preventive Dentistry, Kurunji Venkatramana Gowda Medical College and Hospital, Sullia, Kerala, India

${ }^{2}$ Department of Conservative Dentistry and Endodontics, Subbaiah Institute of Dental Sciences, Shivamogga, Karnataka, India

${ }^{3,5}$ Department of Pedodontics and Preventive Dentistry, Government Dental College and Research Institute, Bengaluru, Karnataka, India.

${ }^{4}$ Deparment of Microbiology, Bowring and Lady Curzon Hospital, Bengaluru, Karnataka, India

${ }^{6}$ Department of Conservative Dentistry and Endodontics, PMS Dental College, Thiruvananthapuram, Kerala, India

Corresponding Author: Vijay Kumar CN, Department of Conservative Dentistry and Endodontics, Subbaiah Institute of Dental Sciences, Shivamogga, Karnataka, India, Phone: +919480047110, e-mail: drvijaycn@gmail.com
}

\section{Source of support: Nil}

Conflict of interest: None

\section{INTRODUCTION}

Long-lasting restoratives and restoration are clinically attractive because they can reduce patient's pain and expense as well as the number of their visits to dental offices. In dentistry, both restorative materials and oral bacteria are believed to be responsible for the restoration failure. Secondary caries is found to be the main reason for the restoration failure of dental restoratives including resin composites and glass-ionomer cements. To make long-lasting restorations, the materials should be made antibacterial. Although numerous efforts have been made on improving antibacterial activities of dental restoratives, most of them have been focused on release or slow-release of various incorporated low molecular weight antibacterial agents such as antibiotics, zinc ions, silver ions, iodine and chlorhexidine. ${ }^{1}$

The beneficial role of fluoride for oral and dental health is well documented and cannot be denied. Among fluoride releasing materials, the glass ionomers or glass silicate materials are most commonly found with keyword "fluoride". Glass ionomers are most commonly used because of their chemical adhesion to the tooth, excellent biocompatibility and the release of fluoride. Over the advantages, these materials are esthetically poor with prolonged setting reaction and compromised mechanical properties. ${ }^{2}$

Resin-modified glass ionomer cements and polyacid modified composites evolved to eliminate the inherent limitations of conventional glass ionomer cements. ${ }^{3}$

Newly introduced into the restorative dentistry, the Giomers. Unlike compomers and glass ionomer cements, here the glass is combined with polyacrylic acid before introducing into the urethane resin. These are considered more advantageous over others due to their ability to release fluoride and recharge of the fluoride content with better biocompatibility, smooth surface finish and good esthetics. ${ }^{4}$

In a clinical perspective, it is crucial that any modifications in the material to analyze improve physical and/or mechanical properties must not compromise 
the fluoride release properties. The key benefits from fluoride release in the oral cavity are the prevention of caries by decreasing the demineralization and increasing the remineralization of dental hard tissue as well as inhibiting growth of the microbial flora. The amount of fluoride released is important to achieve this antibacterial and cariostatic effects. Hence, the fluoride release should not be reduced while improving physical properties or strength of these materials. ${ }^{5}$

Dental caries is one of the significant public health issues in many parts of the world. Caries-associated with bacteria conventionally have been determined by using culture-techniques. ${ }^{6}$

A research study of advanced carious lesions with a unique method carried out by Clarke revealed that advanced carious lesions predominantly contained Bacillus acidophilus odontolyticus (Lactobacillus) followed by S. mutans in initial carious lesions.

Hence, this research aimed at to evaluate and compare the antimicrobial efficacy of giomer (Beautifil flow plus, Shofu Inc., Kyoto, Japan) and compomer (Dyract XP, Dentsply, Germany) against the bacteria which initiates the dental caries, S. mutans and the bacteria which leads to the progression of dental caries, L. acidophilus.
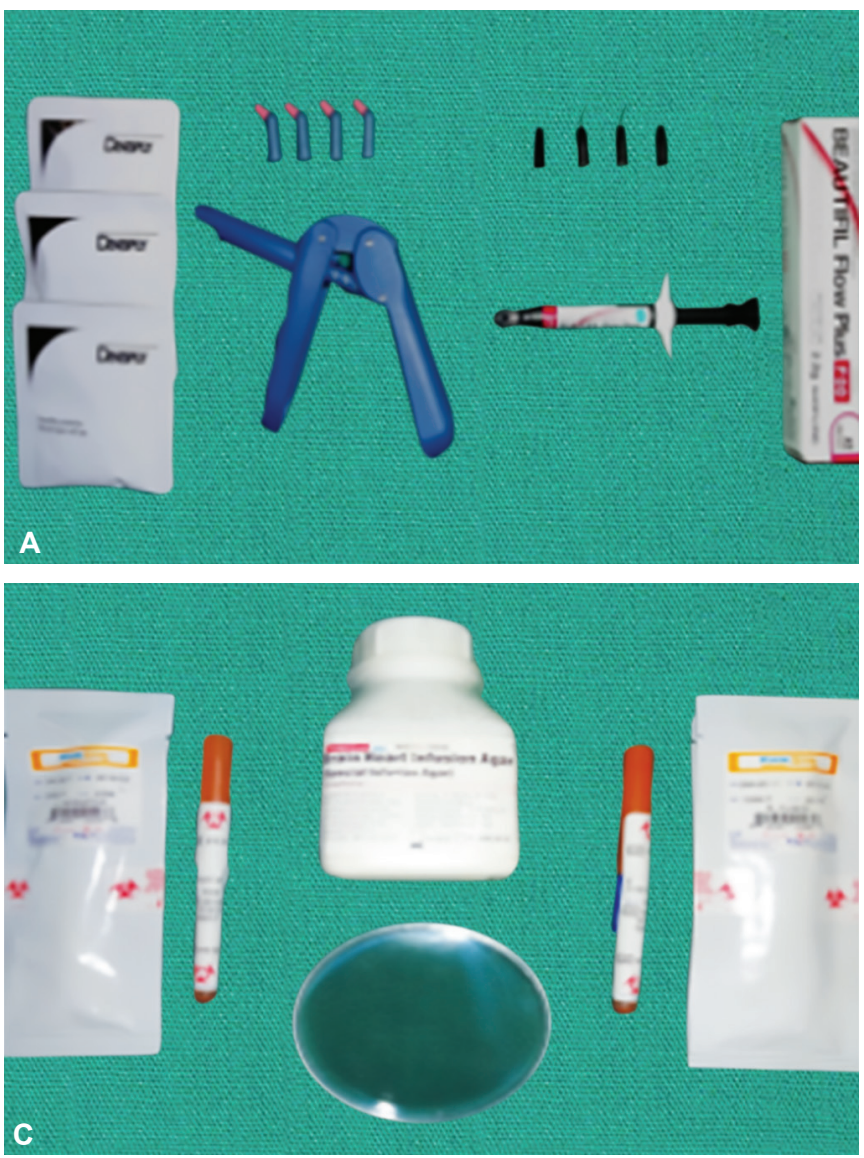

\section{MATERIALS AND METHODS}

This research was conducted in the Bowring Lady Curzon Hospital, Bengaluru. The test materials evaluated were Giomer, Beautifil Flow Plus (SHOFU INC., Kyoto, Japan) and Compomer, Dyract XP (Dentsply, Germany) the standard specimens of $S$. mutans (ATCC 25175) and L. acidophilus (ATCC 4356) (Fig. 1.).

\section{Preparation of Culture Media (Fig. 2A)}

Strains collected from standard culture were inoculated into the Brain Heart Infusion broth for 48 hours at $37^{\circ} \mathrm{C}$. L. acidophilus was incubated anaerobically in an anaerobic jar, and S. mutans was incubated microaerobically in $\mathrm{CO}_{2}$ jar. The growth of microorganism was confirmed by turbidity and inoculated into the Rugosa agar selective media for the growth of L. acidophilus and Streptococcus species into the blood Agar. Then they were checked for colony characteristics, and the inoculums were prepared by comparing the McFarland's turbidity standards, i.e., $10 .^{5}$ $10 \mu \mathrm{L}$ of this inoculums suspension will be pipetted out onto a sterile BHI agar plate and spread with a sterile cotton swab to get a lawn culture of the bacteria. Similar lawn cultures were done for other bacteria.
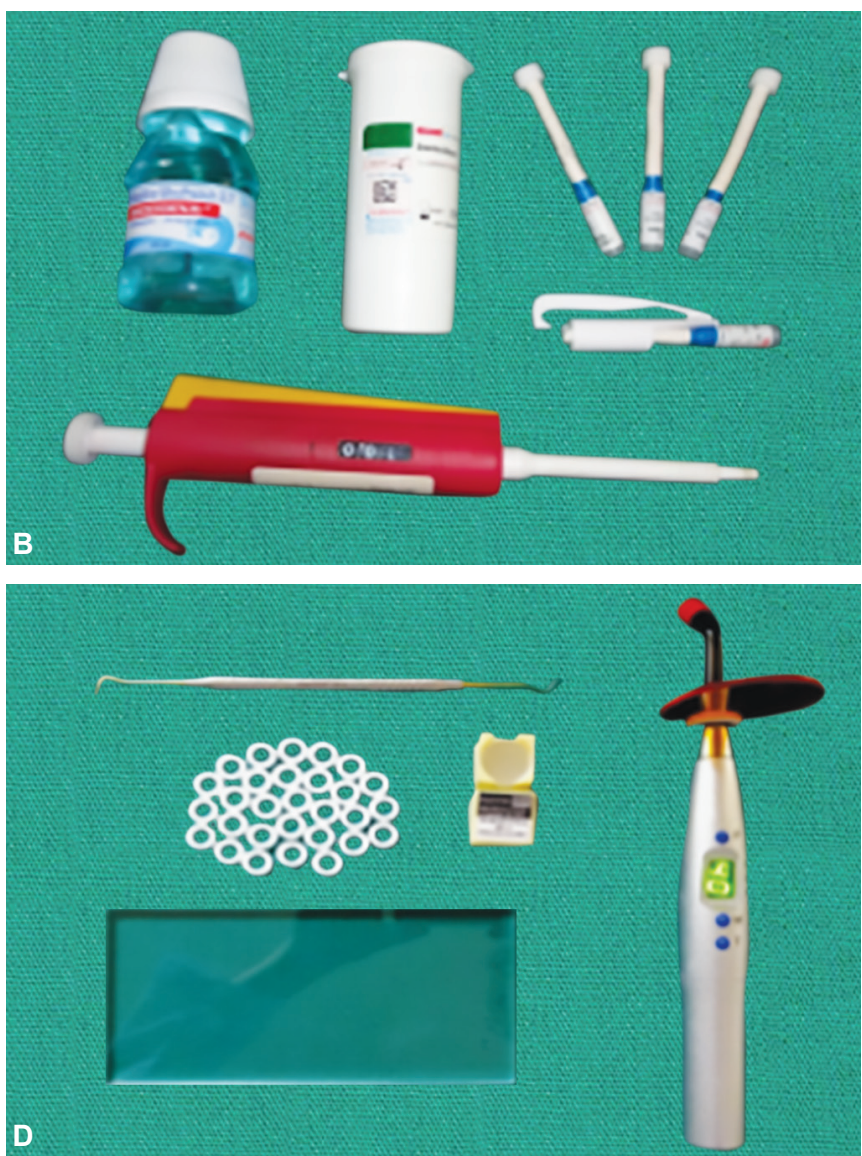

Figs 1A to D: (A) Test materials: COMPOMER, Dyract XP and GIOMER, Beautifil flow plus; (B) Control: Chlorhexidine digluconate, Filter Paper Disc, Micropipette; (C) BHI agar, Petri dishes, lyophilized ATCC strains of test organisms; (D) Armamentarium for specimen preparation: Teflon coated hand instrument, custom made Teflon ring mould, glass covers, glass slab, LED light curing unit 


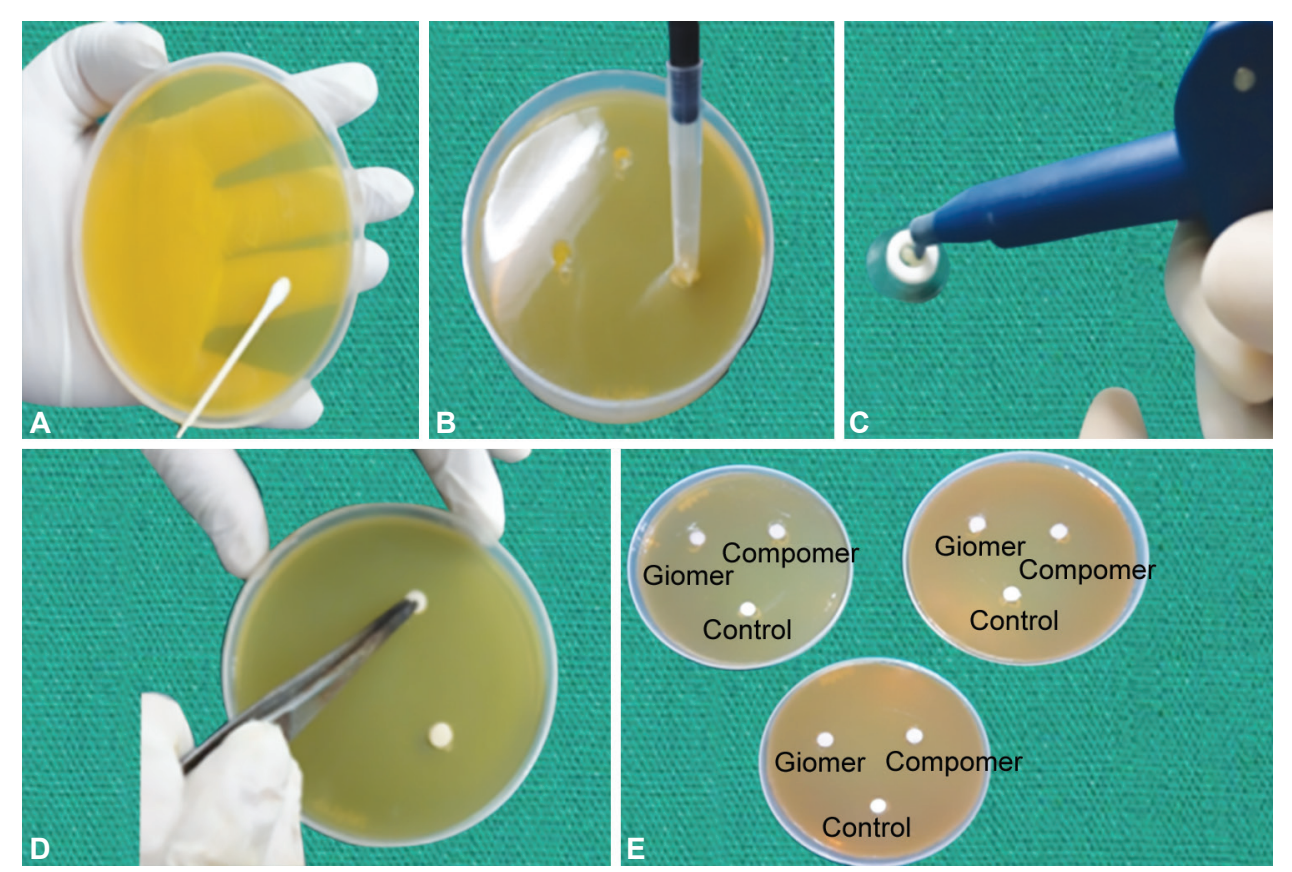

Figs 2A to E: (A) Preparation of lawn culture; (B) Preparation of wells; (C) Preparation of specimens; (D and E) Placement of specimens and control group

\section{Preparation of Wells (Fig. 2B)}

In each sterilized Petri dish $(20 \times 100 \mathrm{~mm})$, wells measuring $6.5 \mathrm{~mm}$ in diameter and $2 \mathrm{~mm}$ in depth were made in each plate using a blunt end of a micropipette tip. Three such wells were made in each petri dish. Five Petri dishes for each bacteria and a total of ten Petri dishes were used for two bacteria, as the study was done in triplicate.

\section{Preparation of Specimens (Fig. 2C)}

The test specimens for both the dental materials were prepared using a custom made teflon ring mold with a diameter of $6.5 \mathrm{~mm}$ and a thickness of $2 \mathrm{~mm}$. The giomer (Beautifil flow plus, Shofu Inc.) and compomer (Dyract XP, Dentsply) specimens were prepared by incremental insertion into the mold with the plastic instruments followed by sandwiching between two cover glasses and light curing for 40 s on each side. Ten microliters of aqueous $0.2 \%$ chlorhexidine digluconate (Hexidine mouthwash-ICPA Health Products Ltd., India) was applied to sterile filter paper discs, which was used as a positive control. These samples were sterilized by autoclaving.

\section{Incubation of Sample (Figs 2D and E)}

Lactobacillus acidophilus (L. acidophilus) was incubated in an anaerobic jar, and S.mutans was incubated for 120 minutes at room temperature for uniform dispersion and then incubated microaerobically in carbon dioxide jar. The agar plates incubated at $37^{\circ} \mathrm{C}$ for 24 hours with Streptococcus species and 48 hours with L. acidophilus.

\section{Measurement of Inhibition Zones (Figs 3 and 4)}

The culture plates were incubated for 24 hours at $37^{\circ} \mathrm{C}$. The antibacterial property was measured at 24 hours, 48 hours and 7 days for each group. After incubation, the plates were taken out of the incubator and the bacterial inhibition zones were evaluated and compared in millimeters with caliper digitally. Measurements were taken at the greatest distance between two points at the outer limit of inhibition halo formed around the wells. This measurement was reevaluated three times for an average reading and the mean was calculated for each well. For each test material against each bacteria, measurements were made in multiples of three. The mean values were evaluated statistically.

\section{RESULTS}

In this agar diffusion test, The culture plates were placed in the incubator for 24 hours at $37^{\circ} \mathrm{C}$. The antibacterial activity was evaluated at 24 hours, 48 hours and 7 days for each group in triplicates. After incubation, the plates were taken out of the incubator and the zones of bacterial inhibition were recorded in millimeters using a digital caliper. Measurements were taken at the greatest distance between two points at the outer limit of inhibition halo formed around the wells. This measurement was repeated three times and the mean was calculated for each well. The mean zones of inhibition produced were recorded after 24 hours, 48 hours, and 7 days for both the test materials.

The antibacterial activity of test material compomer (Dyract XP, Dentsply, Germany) against S. mutans (ATCC 25175) and L. acidophilus (ATCC 4356) was not statistically 

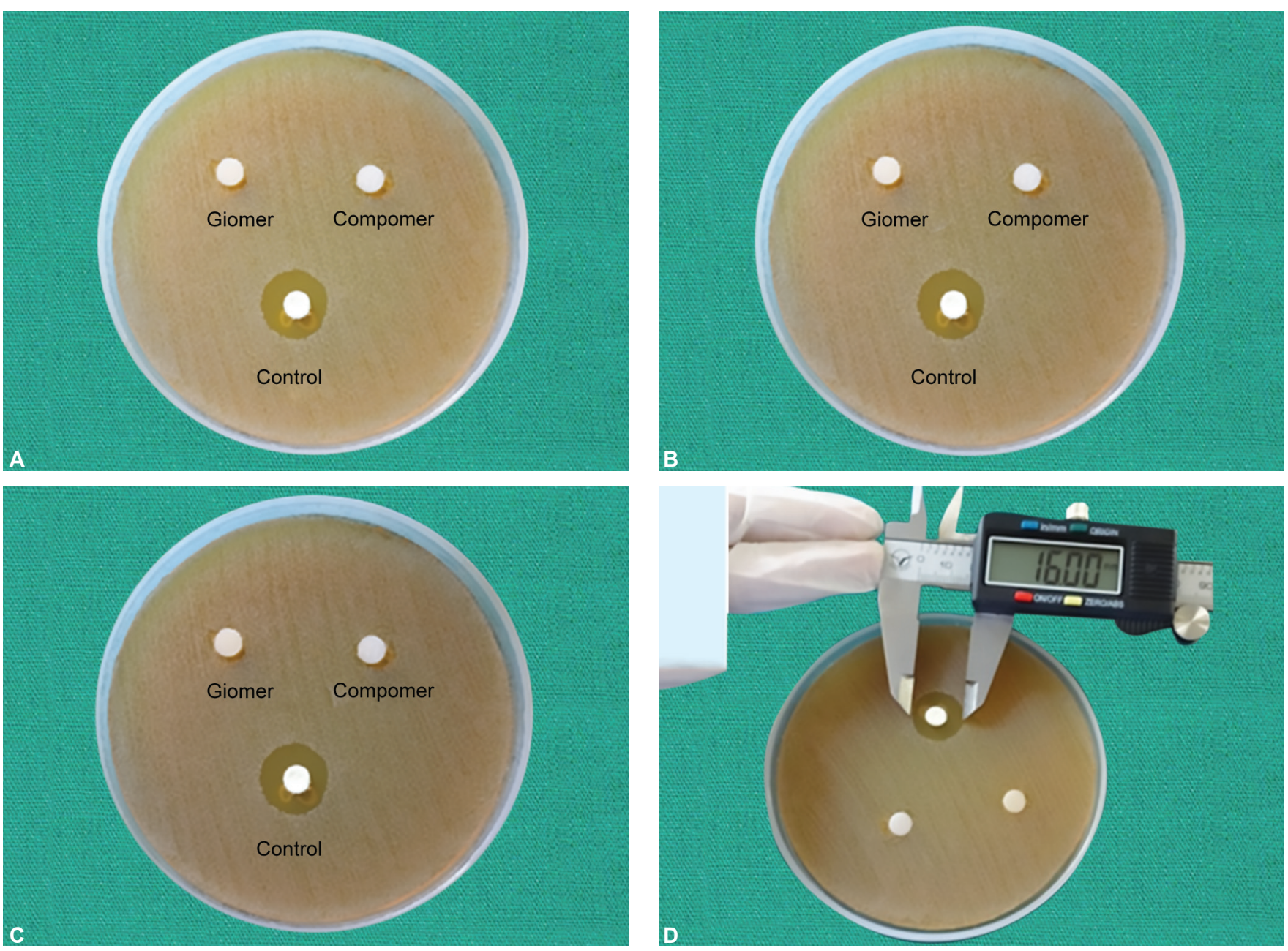

Figs 3A to D: (A) No zone of inhibition seen around giomer and compomer after 24 hours; (B) No zone of inhibition seen around giomer and compomer after 48 hours; (C) No zone of inhibition seen around giomer and compomer after 7 days; (D) Measurement of inhibition zone around the control group with digital caliper

significant at 24 hours, 48 hours and 7 days time interval as shown in Tables 1 and 2.

The antibacterial activity of control group (chlorhexidine digluconate) showed a total mean zone of inhibition of $(15.20 \pm 1.01) \mathrm{mm}$ which was statistically significant against $S$. mutans (ATCC 25175,) and against L. acidophilus (ATCC 4356) showed a total mean zone of inhibition of $(15.55 \pm 0.99) \mathrm{mm}$ as shown in as shown in Table 3.

Statistical analysis for comparison of test materials giomer (Beautifil Flow Plus, Shofu Inc., Kyoto, Japan) and compomer (Dyract XP, Dentsply, Germany) with control group (chlorhexidine digluconate) with respect to size of inhibition zones against S. mutans (ATCC 25175) and L. acidophilus (ATCC 4356) was not possible as the test materials did not show any antibacterial action as shown in Graphs 1 and 2.

Both the test materials giomer (Beautifil Flow Plus, Shofu Inc., Kyoto, Japan) and compomer (Dyract XP, Dentsply, Germany) did not show any antibacterial effect in 24 hours, 48 hours and 7 days interval, however, the control group (chlorhexidine digluconate) showed better antibacterial effect against $S$. mutans and L. acidophilus in all time intervals as shown in Graphs 3 and 4.

\section{DISCUSSION}

Acids produced by the bacteria play a vital role in the development of dental caries. Different techniques used for excavation of carious lesions but none of them eradicate the bacteria. Thus, antimicrobial property of restorative material play major role in preventing recurrent caries. ${ }^{7}$ Hence, this study aimed to evaluate the antibacterial efficacy of giomer (Beautifil Flow Plus, Shofu Inc., Kyoto, Japan) and compomer (Dyract XP, Dentsply, Germany) against bacteria responsible for initiation and progression of caries, S. mutans (ATCC 25175) and Lactobacillus acidophilus (ATCC 4356), respectively.

\section{Giomers}

A relatively new member of this group was developed in an attempt to improve the physical, mechanical, esthetic, and biological properties of the existing glass ionomers. This is a hybrid material and the modification has been made in the filler component. The pre-reacted glass (PRG) fluoroaluminosilicate particles are added to poly acids forming a glass ionomer matrix construct followed by 

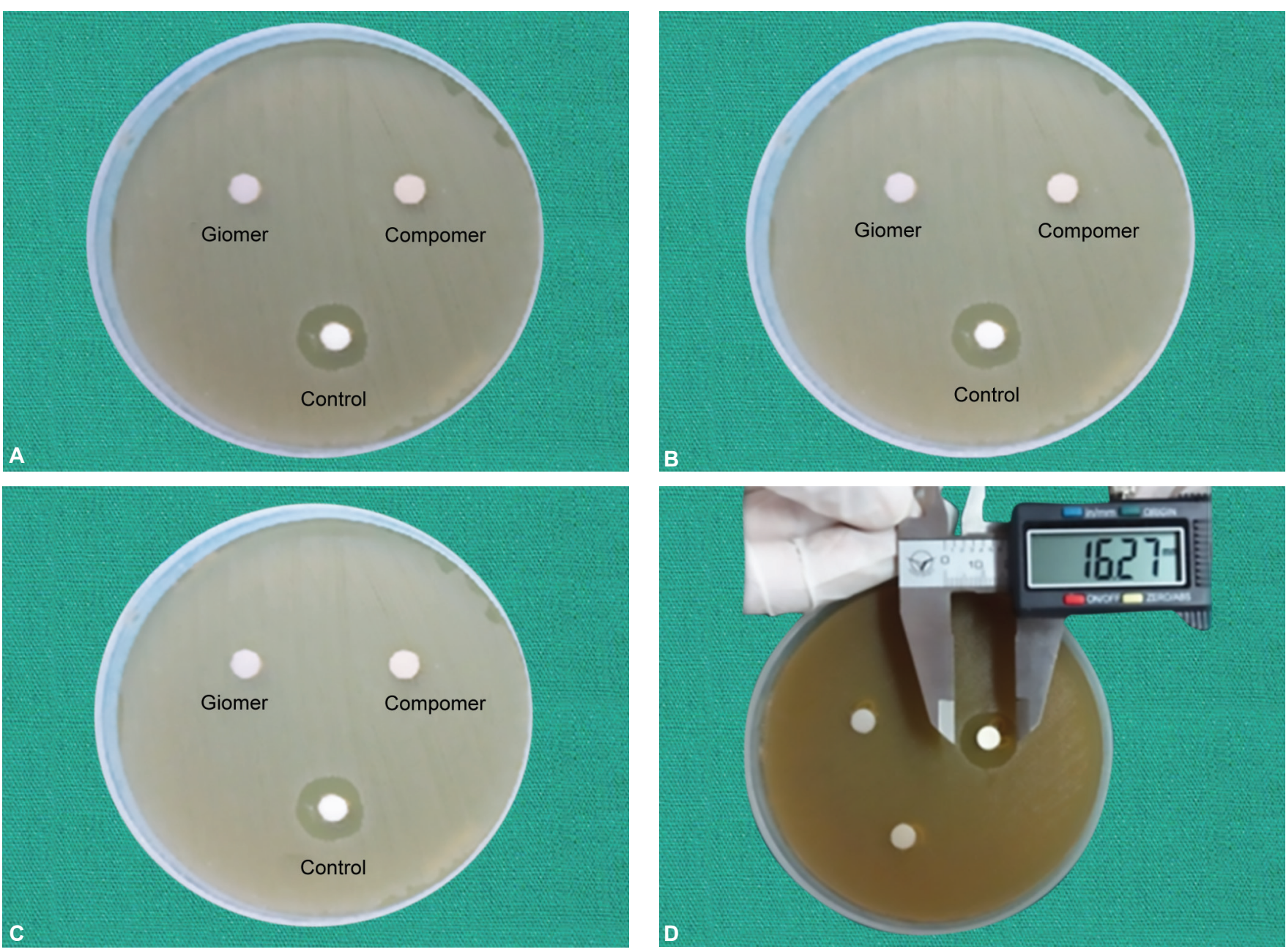

Figs 4A to D: (A) No zone of inhibition seen around giomer and compomer after 24 hours; (B) No zone of inhibition seen around giomer and compomer after 48 hours; (C) No zone of inhibition seen around giomer and compomer after 7 days; (D) Measurement of inhibition zone around the control group with digital caliper

Table 1: Mean zone of inhibition observed as a function of use of giomer against Streptococcus mutans [ATCC 25175] and Lactobacillus acidophilus [ATCC 4356]

\begin{tabular}{lllll}
\hline Bacteria & Time & $N$ & Mean $\pm S D$ & $S E$ \\
\hline \multirow{3}{*}{ Streptococcus mutans } & $24 \mathrm{~h}$ & 3 & $0.00 \pm 0.00$ & 0.00 \\
& $48 \mathrm{~h}$ & 3 & $0.00 \pm 0.00$ & 0.00 \\
& 7 days & 3 & $0.00 \pm 0.00$ & 0.00 \\
\hline & Total & 9 & $0.00 \pm 0.00$ & 0.00 \\
\hline \multirow{4}{*}{ Lactobacillus acidophilus } & $24 \mathrm{~h}$ & 3 & $0.00 \pm 0.00$ & 0.00 \\
& $48 \mathrm{~h}$ & 3 & $0.00 \pm 0.00$ & 0.00 \\
& 7 days & 3 & $0.00 \pm 0.00$ & 0.00 \\
\hline & Total & 9 & $0.00 \pm 0.00$ & 0.00 \\
\hline
\end{tabular}

Table 3: Mean zone of inhibition observed as a function of use of Control group against Streptococcus mutans

[ATCC 25175] and Lactobacillus acidophilus [ATCC 4356]

\begin{tabular}{lllll}
\hline Bacteria & Time & $N$ & Mean $\pm S D$ & $S E$ \\
\hline \multirow{3}{*}{ Streptococcus mutans } & $24 \mathrm{~h}$ & 3 & $15.02 \pm 0.96$ & 0.32 \\
& $48 \mathrm{~h}$ & 3 & $15.72 \pm 0.83$ & 0.27 \\
& 7 days & 3 & $14.85 \pm 1.12$ & 0.37 \\
\hline & Total & 9 & $15.20 \pm 1.01$ & 0.19 \\
\hline \multirow{4}{*}{ Lactobacillus acidophilus } & $24 \mathrm{~h}$ & 3 & $15.47 \pm 1.01$ & 0.33 \\
& $48 \mathrm{~h}$ & 3 & $15.83 \pm 0.53$ & 0.17 \\
& 7 days & 3 & $15.35 \pm 1.32$ & 0.44 \\
\hline & Total & 9 & $15.55 \pm 0.99$ & 0.19 \\
\hline
\end{tabular}

Table 2: Mean zone of inhibition observed as a function of use of compomer against Lactobacillus acidophilus [ATCC 4356] and Streptococcus mutans [ATCC 25175]

\begin{tabular}{lllll}
\hline Bacteria & Time & $N$ & Mean $\pm S D$ & SE \\
\hline \multirow{3}{*}{ Streptococcus mutans } & $24 \mathrm{~h}$ & 3 & $0.00 \pm 0.00$ & 0.00 \\
& $48 \mathrm{~h}$ & 3 & $0.00 \pm 0.00$ & 0.00 \\
& 7 days & 3 & $0.00 \pm 0.00$ & 0.00 \\
\hline & Total & 9 & $0.00 \pm 0.00$ & 0.00 \\
\hline \multirow{4}{*}{ Lactobacillus acidophilus } & $24 \mathrm{~h}$ & 3 & $0.00 \pm 0.00$ & 0.00 \\
& $48 \mathrm{~h}$ & 3 & $0.00 \pm 0.00$ & 0.00 \\
& 7 days & 3 & $0.00 \pm 0.00$ & 0.00 \\
\hline & Total & 9 & $0.00 \pm 0.00$ & 0.00 \\
\hline
\end{tabular}

mixing with a resin matrix. The manufacturers of these materials have claimed that they show better physical and mechanical properties, better biocompatibility, and more effective F release. Giomers can be classified between GICs and compomers as PRG technology. The fluoroaluminosilicate glasses are modified before their inclusion in a dimethacrylate resin matrix to allow the release of $\mathrm{F}$.

\section{Compomers}

Polyacid-modified resin composites (compomers) are synthesized using the components of resin composites: 


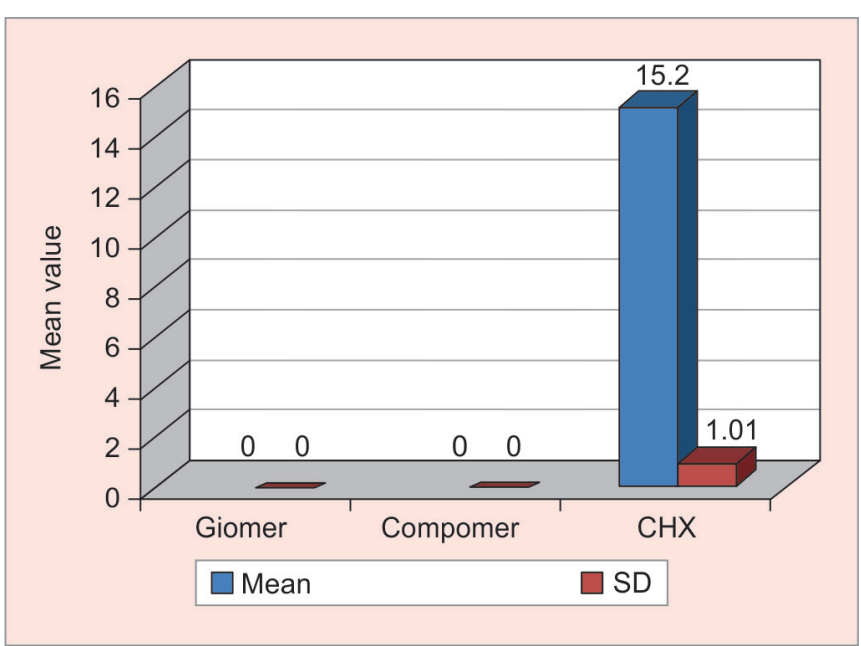

Graph 1: Comparison of test materials and control group with respect to size of inhibition zones with Streptococcus mutans

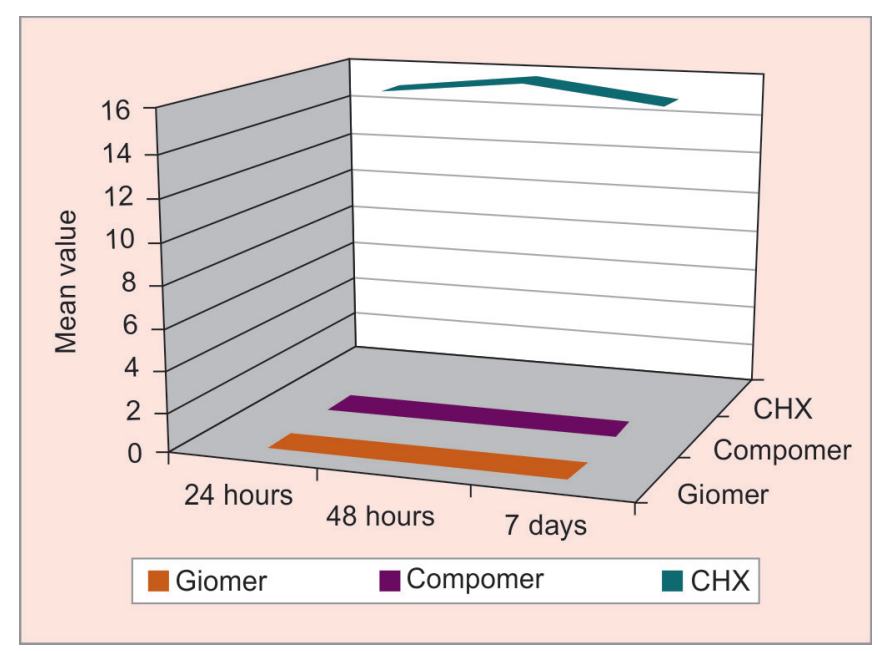

Graph 3: Comparison of antibacterial activity of test materials and control group with respect to time period against Streptococcus mutans.

bisphenol glycidyl dimethacrylate (BISGMA) and GIC (ion leaching glass silicate fillers). Compomers initially set by photopolymerization and this is followed by an acid-base reaction responding to water sorption. The polyacid modification is used to improve the esthetic and mechanical properties in an attempt to merge the properties of GIC and resin composites in a single material.

The results of our study indicated that both giomer (Beautifil Flow Plus, Shofu Inc., Kyoto, Japan) and compomer (Dyract XP, Dentsply, Germany) did not show any zone of inhibition and were not effective against microorganisms at 24 hours, 48 hours and 7 days of time period, against bacteria responsible for initiation and progression of caries, S. mutans (ATCC 25175) and L. acidophilus (ATCC 4356) respectively, only control group showed a zone of inhibition against S.mutans $(15.20 \pm 1.01)$ and L.acidophilus $(15.55 \pm 0.99)$, therefore the results could not be statistically analyzed. According to this agar diffusion test, none of the test materials was antibacterial because there was low or no solubility

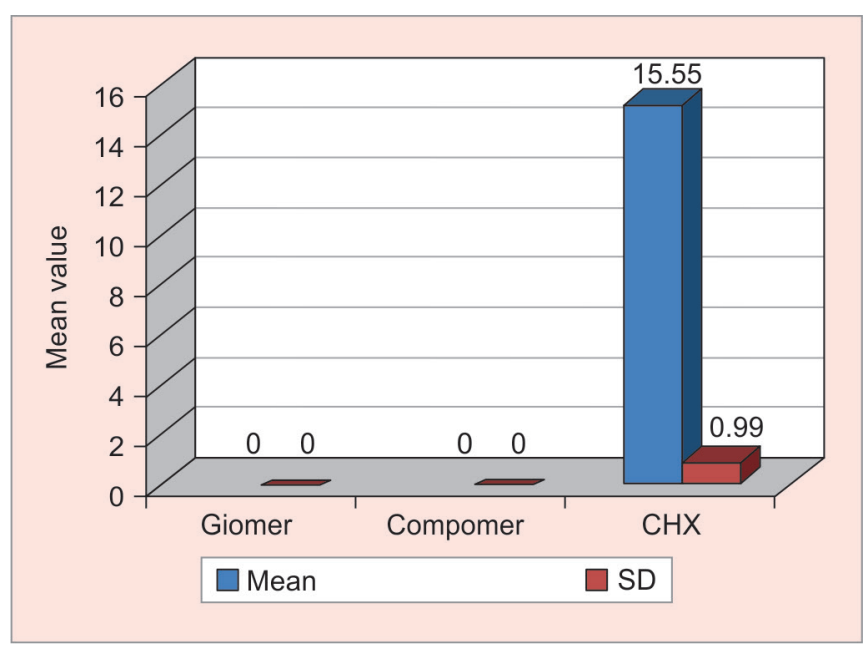

Graph 2: Comparison of test materials and control group with respect to size of inhibition zones with Lactobacillus acidophilus

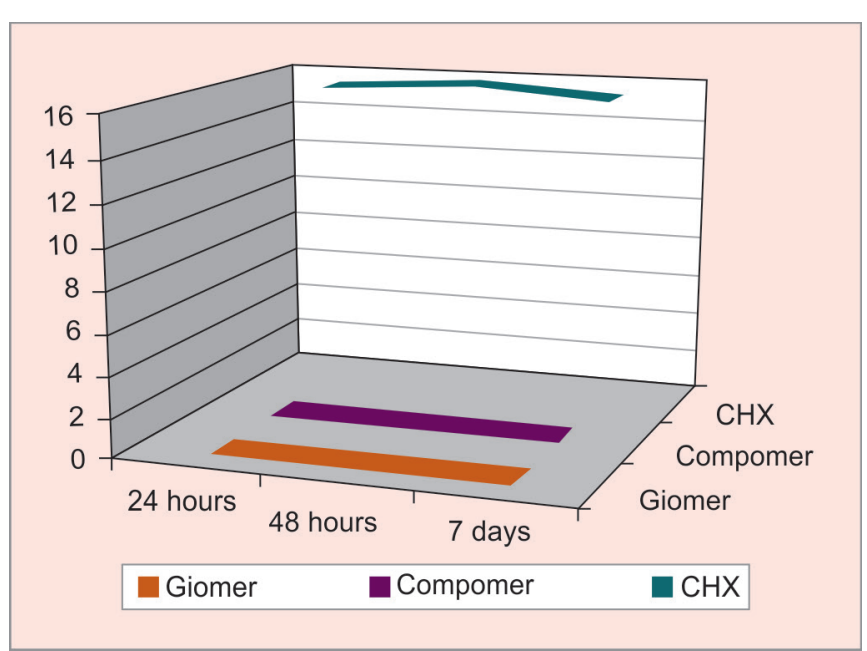

Graph no.4: Comparison of antibacterial activity of test materials and control group with respect to time period against Lactobacillus acidophilus

of the antibacterial components from the test materials into the surrounding aqueous milieu.

There are different techniques used to assess antibacterial action namely, agar absorption assay, agar dilution assay, disk diffusion assay, well diffusion assay, broth dilution assay. The agar plate diffusion test used in the present study is an accepted method to initially discriminate the antibacterial activity among dental materials. ${ }^{8}$

Studies revealed various results on fluoride release from dental restorative materials. Prolong release of fluoride and intimacy of fluoride with restoration is important for effective fluoride ion exchange. This helps decrease the acid solubility of enamel and dentin. The contact of fluorides with the tooth structure forms soluble fluoride salts such as calcium fluoride, which increases the resistance of tooth for acid dissolution. Thus fluoride in the aqueous phase at the apatite crystal surface may have a vital role in the prevention of enamel and dentin dissolution, thereby imparting a caries inhibitory action. ${ }^{9}$ 
There are few attempts to correlate the effect of acidogenic bacteria on fluoride release. These studies revealed that the bacteria would disrupt the transmembrane proton shell there by decrease the ability of cells to deliver the fluoride ions. Because of this, there is no general agreement that the antibacterial effects of fluoride contribute to caries prevention. ${ }^{10}$

Most of the studies concluded that $200-300 \mu \mathrm{g} / \mathrm{cm}^{2}$ release fluoride per month is essential for prevention of demineralization. ${ }^{11}$ According to Jacobson et al. 3 ppm fluoride concentration is needed for remineralization. Research revealed that 50-80 ppm fluoride ion concentration at the tooth-restorative interface will help inhibit the caries initiation. ${ }^{12}$

Matalon et al. in his study told none of the composite resins used in his study affect the bacterial growth. Interestingly freshly cured composite resins support the bacterial growth. Recent studies showed that $0.16-0.31 \mathrm{mmol} / \mathrm{L}$ of fluoride ion concentration is essential for antibacterial efficacy over streptococci under laboratory settings. ${ }^{13}$

In the present study, agar diffusion method is used to evaluate the antibacterial property of restorative materials (giomer and compomer) against the selected microorganism. This method is effective and proven to be accurate. Disadvantages of this method include, it fails to distinguish between bacteriostatic and bactericidal effects. Moreover, this test does not give information about the viability of microorganisms inside the inhibition zone. Yap et al. in his in vitro experiment revealed that fluoride-containing restorative material does not have any antibacterial property.

However, varying results could be obtained, as it is known that the diffusibility of an antimicrobial agent depends on its size, form of filler particles, and its concentration in the material. In addition, the diffusibility of ions ( $\mathrm{F}-, \mathrm{Ca}++, \mathrm{Al}+++, \mathrm{OH}-)$ from GIC depends on the $\mathrm{pH}$ of the environment. ${ }^{14}$

However, The results of our study indicated that both giomer (beautifil Flow Plus, Shofu Inc., Kyoto, Japan) and compomer (Dyract XP, Dentsply, Germany) could not inhibit the growth of bacteria involved in initiation and progression of caries, S. mutans (ATCC 25175) and L. acidophilus (ATCC 4356 ) at 24 hours, 48 hours and 7 days interval.

A study by Turkheim revealed that as the chemical reaction of the cement continues, the antimicrobial ability also proved to be more during this period of time. ${ }^{15}$ Moreover, antibacterial efficacy is more in freshly mixed cement than the set cement. ${ }^{16}$

\section{CONCLUSION}

Within the limitations of this study, it can be concluded that:

- In this study, giomer (Beautifil Flow Plus, Shofu Inc., Kyoto, Japan) and compomer (Dyract XP, Dentsply,
Germany) does not show any antibacterial property against S. mutans and L. acidophilus (Tables 1 and 2 and Graphs 1 and 2).

- After 24 hours, 48 hours and 7 days' time interval both restorative materials (Giomer and Compomer) does not show any antibacterial properties (Tables 1 to 3 and Graphs 1 to 4 ).

\section{CLINICAL SIGNIFICANCE}

Many in vitro studies cannot support the findings that are observed in vivo. This observation suggests that more clinical research is needed to clarify this issue. Hence, clinical research on this topic is of utmost relevance for minimum intervention restorative techniques in dentistry and for promoting oral health.

\section{REFERENCES}

1. Weng Y, Chong VJ, Howard L, Huang R, Gregory RL, Xie D. A novel antibacterial dental resin composite. Journal of Biomaterials and Nanobiotechnology. 2012;3(2):130.

2. Zafar MS. Effects of surface pre-reacted glass particles on fluoride release of dental restorative materials. World Appl Sci J. 2013;28(4):457-462.

3. Dionysopoulos D. The effect of fluoride-releasing restorative materials on inhibition of secondary caries formation. Fluoride. 2014;47(3):258-265.

4. Arora V. Giomer-a new hybrid aesthetic restorative material. J Conserv Dent. 2002;5(4):149-155.

5. El Mallakh BF, Sarkar NK. Fluoride release from glassionomer cements in de-ionized water and artificial saliva. Dental Materials. 1990;6(2):118-122.

6. Aas JA, Griffen AL, Dardis SR, Lee AM, Olsen I, Dewhirst $\mathrm{FE}$, et al. Bacteria of dental caries in primary and permanent teeth in children and young adults. Journal of clinical microbiology. 2008;46(4):1407-1417.

7. Yaman SD, Er O, Yetmez M, Karabay GA. In vitro inhibition of caries-like lesions with fluoride releasing materials. J Oral Sci 2004;46(1):45-50.

8. Mungara J, Philip J, Joseph E, Rajendran S, Elangovan A, Selvaraju G. Comparative evaluation of fluoride release and recharge of pre-reacted glass ionomer composite and nano-ionomeric glass ionomer with daily fluoride exposure: an in vitro study. J Indian SocPedodPrev Dent. 2013;31(4):234-239.

9. Vermeersch G, Leloup G, Vreven J. Fluoride release from glass-ionomer cements, compomers and resin composites. J Oral Rehabil 2001;28(1):26-32.

10. Mohammed NR, Kent NW, Lynch RJ, Karpukhina N, Hill R, Anderson P. Effects of fluoride on in vitro enamel demineralization analyzed by 19F MAS-NMR. Caries Res 2013; 47(5):421-428.

11. DeSchepper EJ, Thrasher MR, Thurmond BA. Antibacterial effects of light-cured liners. American journal of dentistry. 1989;2(3):74-76.

12. Fraga RC, Siqueira JF Jr, de Uzeda M. In vitro evaluation of antibacterial effects of photo-cured glass ionomer liners and dentin bonding agents during setting. J Prosthet Dent. 1996 Nov 76(5):483-486. 
13. Boeckh C, Schumacher E, Podbielski A, Haller B. Antibacterial activity of restorative dental biomaterials in vitro. Caries Research. 2002;36(2):101-107.

14. Matalon S, Slutzky H, Weiss EI. Surface antibacterial properties of packable resin composites: part I. Quintessence Int. 2004; Mar 35(3):189-193.
15. Turkheim HJ. In vitro experiments on the bactericidal effect of zinc oxide eugenol cement on bacteria-containing dentin. Journal of Dental Research. 1955;34:295-301.

16. Shirani FA, Havaei A, Malekipour M, Sharafi M. Surface antibacterial properties of four tooth-colored restorative materials. Journal of Dentistry of Tehran University of Medical Sciences. 2008;5(1):1-6. 